\title{
O trabalho das equipes da saúde família: um olhar sobre as dimensões organizativa do processo produtivo, político-ideológica e econômica em Juiz de Fora ${ }^{1}$
}

DENISE BARBOSA DE CASTRO FRIEDRICH*

CÉLIA REGINA PIERANTONI**

Trata-se de um estudo de caso, com o objetivo de analisar o trabalho das equipes de saúde da família. Foram realizadas entrevistas e observação direta das equipes. A organização do processo produtivo se caracteriza por intensa divisão de trabalho. A demanda do usuário e assistência à saúde são os temas dessa dimensão. A dimensão político-ideológica é permeada de práticas de poder diversas, e temas como modelo assistencial, modelo gerencial e a informação entre equipes e gestores emergiram de forma a explicitar tal dimensão. Já a dimensão econômica se caracteriza por vínculos e remunerações diferenciadas para trabalhadores que compartilham o mesmo grau de responsabilidade. As falas nessa dimensão destacaram os temas: modalidades de vínculos, remuneração diferenciada e direitos sociais. Acredita-se que essas constatações podem possibilitar o incremento de ações mais resolutivas pelos trabalhadores, pelos gestores e pelo controle social na atenção básica de saúde do município.

Palavras-chave: Saúde Pública; Programa de Saúde da Família; trabalho/ economia; trabalhadores; condições de trabalho.

Recebido em: 23/03/2006.

Aprovado em: 02/05/2006. 


\section{Introdução}

Uma das alternativas do Sistema Único de Saúde (SUS) atualmente utilizadas para minimizar os impactos negativos do modelo curativo de assistência à saúde, realizado através do trabalho parcelado, é o trabalho desenvolvido na atenção básica pelas equipes de Saúde da Família.

Por acreditar que o Programa de Saúde da Família (PSF) é um dos caminhos que podem reorganizar de fato e contribuir para o SUS se efetivar nos municípios brasileiros, procurou-se desenvolver um estudo sobre o trabalho das equipes de Saúde da Família, a partir da seguinte questão norteadora: de que maneira se organiza o trabalho nas equipes de Saúde da Família?

O questionamento orientou a busca de fenômenos intrínsecos ao trabalho das equipes de Saúde da Família do município de Juiz de Fora, de forma a proporcionar uma reflexão sobre o processo que as envolve. Isso é justificado pela necessidade de evidenciar novos caminhos para que trabalhadores e instituições dos municípios de médio porte conquistem maior resolubilidade na atenção básica. Nessa perspectiva, este estudo tem como objetivo analisar o trabalho das equipes de Saúde da Família no município de Juiz de Fora, na dimensão organizativa do processo produtivo, na dimensão político-ideológica e na dimensão econômica.

Para tanto, partindo do proposto por Santana (2001), estudou-se o trabalho das equipes de Saúde da Família:

- na dimensão organizativa do processo produtivo, em que as relações de trabalho se estabelecem, indispensavelmente, entre os diversos atores que interagem no processo produtivo;

- na dimensão político-ideológica, em que as relações de trabalho se configuram nas relações de poder e espaço de geração de conflitos;

- na dimensão econômica, isto é, na qual as relações de trabalho se configuram na permuta entre a capacidade de trabalho por remuneração.

\section{Metodologia}

Com uma abordagem qualitativa, foi realizado estudo de caso (YIN, 2003) para apreender o trabalho das equipes de Saúde da Família. Foram 
utilizadas, como fonte de evidências, a observação direta do trabalho das equipes e as entrevistas individuais.

No período de realização da pesquisa, a estratégia de Saúde da Família em Juiz de Fora possuía 80 equipes credenciadas no Ministério da Saúde (MS) e cobria $42 \%$ do município. Atualmente o município conta, segundo o Ministério da Saúde, com uma cobertura de 48,7\% do PSF, possuindo 82 equipes e dois Programas de Agentes Comunitários de Saúde (BRASIL, 2005).

Foram realizadas 90 horas de observação direta do trabalho das equipes. As entrevistas com os componentes das equipes e gestores foram a fonte de evidências mais rica na condução deste estudo, seguindo um protocolo previamente elaborado e testado, através de entrevistas-piloto que ocorreram em novembro de 2003. Um médico, um enfermeiro, um agente comunitário e um auxiliar de enfermagem de uma equipe foram entrevistados e, a partir de suas falas, foi possível reorganizar o instrumento utilizado. Vale destacar que essa equipe fez parte da investigação somente para testagem e adequação do instrumento de coleta de evidências.

As demais entrevistas foram realizadas de fevereiro de 2004 a maio de 2004, orientadas pelo instrumento que constou de identificação do entrevistado e de três questões, a saber: 1) descreva como se estabelece a divisão de trabalho entre os componentes de sua equipe; 2) identifique as divergências ou convergências de interesses do trabalho de sua equipe e entre sua equipe e os dirigentes; 3) descreva a remuneração e vínculos de trabalho dos componentes das equipes de Saúde da Família.

Algumas perguntas complementares foram inseridas quando necessário. As 49 entrevistas tiveram duração de 20 a 60 minutos, foram gravadas e depois transcritas pela pesquisadora. Do total de entrevistados, 39 eram do sexo feminino e 10 do sexo masculino. Optou-se por iniciar as entrevistas com os profissionais que compõem o quadro de coordenação das equipes em nível central (gestores). Foram entrevistados seis trabalhadores, quatro médicos, um dentista e um engenheiro.

Os componentes das equipes de Saúde da Família lotados nas UBS foram entrevistados posteriormente. Seis equipes foram entrevistadas e, no tempo em que ocorreram reincidências das informações (MINAYO, 1994), ou seja, quando não surgiram evidências novas, o que ocorreu na trigésima nona entrevista, estendeu-se a coleta a mais duas equipes. Nas falas dessas equipes não houve novas evidências, o que permitiu encerrar o processo. 


\section{Resultados e discussão}

\section{Dimensão organizativa do processo produtivo}

Nesta dimensão emergiram dois temas: a demanda do usuário e a assistência à saúde.

\section{A demanda do usuário}

Para o Ministério da Saúde (BRASIL, 2002), a estratégia de Saúde da Família organiza e diminui a demanda espontânea, à medida que os problemas de saúde coletivos vão sendo identificados e uma abordagem coletiva é colocada em prática. Ao contrário do que se espera da estratégia de Saúde da Família, as respectivas unidades, no município de Juiz de Fora, ainda estão abarrotadas de demanda espontânea. A fala de um dos entrevistados expressa que a demanda espontânea é uma realidade no município (sic): "a população é grande demais e a gente realmente não consegue fazer saúde da família, a gente atende uma média de 100 pessoas em uma manhã aqui na unidade, isso todo dia, de segunda a sexta" (enfermeira 7).

A demanda espontânea do usuário também se mostrou indutora das atividades realizadas pela equipe:

O usuário chega e ele tem uma demanda pessoal em relação à saúde ou mesmo de sua família e aí vai ser tomada uma decisão com relação, à questão, qual atividade que vai se fazer, se vai ser feita uma consulta, se vai ser feita uma visita, um encaminhamento esse tipo de coisa (médico 4).

Segundo Nogueira (1997, p. 182):

a assistência em saúde é, entre outras coisas, um processo de intensa relação entre quem presta e quem consome o serviço. Mais tipicamente que em outros setores da economia de serviço, vamos encontrar aí o fato peculiar de que o usuário é um fornecedor de valores de uso substantivos de tal modo que ele é um co-partícipe do processo de trabalho.

Nesse sentido, acredita-se que, apesar de ser um dos objetivos do PSF organizar a demanda, em Juiz de Fora isso se destaca como problema. O serviço do PSF no município ainda não deu conta de salientar para a população usuária a dinâmica da prestação desse serviço. Pode-se inferir que tal fato ocorra porque o município já possuía um serviço de saúde estruturado, anterior à implantação do PSF, que atendia em parte às necessidades de cura da população. 
As ações preestabelecidas do PSF (atenção ao diabético, hipertenso, pré-natal, entre outras) acabam por inibir outras ações da estratégia, como o levantamento de problemas de saúde próprios da localidade, pelos usuários e pelos trabalhadores. Corroborando Vasconcellos (1999), pode-se afirmar que o desafio do PSF é mostrar sua capacidade de integração com serviços locais de saúde bem estruturados, redefinindo qualitativamente seu modelo de atuação. Tornase um desafio para o município organizar a demanda e redefinir o modelo de atenção, que é necessário para dar maior resolubilidade aos problemas de saúde de sua população.

\section{A assistência à saúde}

Pode-se verificar que as atividades assistenciais realizadas pelos trabalhadores de saúde seguem prioritariamente o estabelecido pelo MS e pela NOAS (BRASIL, 2001). As atividades assistenciais do agente comunitário são visitas às famílias cadastradas, mobilização da comunidade (para que a mesma procure resolver seus problemas de saúde com a equipe de Saúde da Família), orientações quanto a medicações, identificação de indivíduos e/ou famílias que necessitem de atendimento domiciliar e grupos educativos: "Os ACS, eles fazem a visita domiciliar com a busca ativa de gestantes, da mãe que está amamentando, da criança desnutrida, dos hipertensos, dos diabéticos, né? Eles fazem isso e a gente procura atender dentro da proposta de Saúde da Família" (assistente social 1).

Os médicos realizam, na maioria das vezes, consultas de demanda, consulta de grupos de hipertensos e diabéticos, consultas de pré-natal, preventivos, puericultura, visita domiciliar, como se vê a seguir (sic): "Os médicos do programa de Saúde da Família fazem um trabalho de prevenção através de grupos de hipertensos, puericultura, pré-natal e o trabalho com os desnutridos" (auxiliar de enfermagem 1).

As atividades assistenciais realizadas pelas enfermeiras são atividades de demanda programada - isto é, agendadas previamente, como pré-natal de baixo risco, preventivo, visita domiciliar, acolhimento, grupos educativos - além das atividades burocráticas e administrativas, como o preenchimento de formulários e a supervisão de auxiliares e agentes comunitários, como pode ser confirmado no enunciado ( sic): “A enfermeira da nossa área faz grupos de direitos reprodutivos, grupo de climatério, gestantes, atendimento no acolhimento, algumas receitas ela pode passar" (ACS 4). 
As atividades realizadas pelos auxiliares de enfermagem nas equipes de Saúde da Família são assim retratadas (sic): "O auxiliar faz coleta de material, visita domiciliar, injeção, nebulização, curativo, né? Faz a coleta de sangue, anotam também agendamento de consulta, agendamento de exames, essas coisas" (assistente social 2).

Embora o trabalho das equipes tenha como pressuposto produzir saúde e nessa concepção de produção de saúde esteja atrelado à necessidade de um trabalho que compartilhe saberes e práticas (CAMPOS, 1997) - respeitando as especificidades, logicamente - os auxiliares de enfermagem, em suas atividades, continuam reiterando o modelo de atenção curativo.

As assistentes sociais são vinculadas a uma equipe, mas prestam assistência à saúde nas comunidades da área de abrangência de, no mínimo, três equipes. Elas realizam grupos educativos, atendimentos individuais, cadastram usuários para o programa de saúde mental, fazem visita domiciliar, acolhimento e participam das reuniões dos conselhos locais de saúde.

A fala a seguir demonstra algumas das atividades realizadas pelas assistentes sociais junto às equipes de Saúde da Família em Juiz de Fora (sic): "A assistente social faz o encaminhamento para saúde mental, essas pessoas passam pela assistente social aqui. Ela tem outro trabalho, que é com as crianças desnutridas, ela encaminha as crianças de alto risco lá para baixo" (ACS 3).

Os dentistas, no momento da investigação, ainda não integravam as equipes de Saúde da Família, mas já se delineavam algumas ações conjuntas com os demais trabalhadores. Por exemplo, o atendimento odontológico planejado para as áreas de abrangência do PSF e o contato dos usuários através dos ACS. O enunciado a seguir evidencia tal situação (sic):

O dentista entrou agora no programa, ele tem feito algumas atividades da comunidade junto com o agente comunitário, ele faz uma palestra educativa e depois ele seleciona aquelas famílias que participarão de algum tratamento e parece que a dentista responsável da nossa área vai fazer um grupo de idosos (enfermeira 5).

Enfim, a dimensão organizativa do processo produtivo das equipes de Saúde da Família se caracteriza pela realização de inúmeras atividades e pela intensa divisão de trabalho. As equipes prestam assistência por meio das atividades propostas pelo programa. Tais atividades já existiam anteriormente 
em programas distintos do Ministério da Saúde e agora foram condensadas na estratégia de Saúde da Família.

O processo produtivo é organizado de forma parcelada, fragmentada e isolada. Os trabalhadores se colocam disponíveis para atuar em conjunto, demonstram interesse pelo que fazem, mas a demanda da comunidade pela assistência de saúde tradicional é intensa e forte. Eles se encontram em um espaço de conflito, onde há contradição entre o que é proposto pelo PSF e a vontade dos usuários. Isso implica muitas vezes a total absorção dos trabalhadores em atividades de caráter imediato e pouco resolutivo. Pode-se inferir que esse fato resulta também da ausência de políticas programáticas efetivas, de acordo com a realidade das áreas de abrangência de cada equipe, porque as ações são preestabelecidas e idênticas na maioria das equipes estudadas.

\section{Dimensão político-ideológica}

Os temas que emergiram foram: modelo assistencial, modelo gerencial e informação em saúde.

\section{Modelo assistencial}

Pode-se identificar que o modelo proposto pelo PSF não é o modelo assistencial hegemônico. O modelo curativo, aquele que se organiza através da demanda espontânea, é o predominante no município.

Em Juiz de Fora, apesar de a estratégia Saúde da Família ser uma tentativa de inversão do modelo de assistência vigente, não se consegue superar o modelo de assistência sustentado na atenção à livre demanda; ele é curativo, individual, oneroso e pouco resolutivo frente aos reais problemas de saúde da população. Observou-se que as divergências de interesses entre trabalhadores e dirigentes nascem da contradição do que é proposto como modelo de assistência à saúde e do que realmente se estabelece na realidade das unidades básicas do município.

Os trabalhadores de saúde entrevistados deixam claro, através de suas falas, qual o modelo de assistência predominante no Município (sic): 
a gente está fazendo mais saúde curativa do que preventiva. Você agrada a população quando você dá algo em troca, quando você tem medicação. Ninguém vai querer vir ao grupo se só tem que vir aferir a pressão, isso eles não querem. Eles querem sempre que tenha o remédio (enfermeira 6).

\section{Modelo gerencial}

Observou-se que congrega ações de vários trabalhadores. É um trabalho atrelado às orientações do Ministério da Saúde. Tem pouca autonomia e é centralizado, o que impede um trabalho mais criativo e resolutivo pelas equipes do PSF.

Nós temos um bom relacionamento com a gerência, mas na hora de implementar aquilo que a gente chega em uma concordância, a gente não consegue colocar para frente por causa do problema político, porque a questão que a gente sempre esbarra é o chefe do chefe do chefe e eu acho e o meu colega também fala é muita gente pra mandar remar e um remador só [sic] (médico 6).

Este modelo é baseado na Administração Clássica, pois, como diz Campos (1997, p. 231), ele impõe "um acúmulo das equipes com normas administrativas e padronizações técnicas. [...] a gerência controla e regulamenta toda e qualquer possibilidade imaginável de trabalho". Retira a autonomia dos trabalhadores das equipes que se encontram no núcleo operacional da organização (MINTZBERG, 1995).

\section{Informação em saúde}

A informação é necessária para qualquer decisão que tomemos em nossa vida cotidiana. No trabalho em saúde, a informação se torna imprescindível na tomada de decisões acertadas para melhorar o nível de saúde de determinada população. A fala a seguir demonstra que o trabalho das equipes de Saúde da Família paradoxalmente se desenvolve alijado de informações sobre os resultados gerais de seu próprio trabalho $($ sic):

Eu fiz uma solicitação de atendimento ao rapaz responsável pela informação, lá embaixo e ele falou: Eu vou copiar para você e vou mandar pelo malote. Quando ele foi tirar os resultados na impressora, ele me ligou e disse que 
o responsável falou que não era para mandar, porque vai ser feito um mapa e depois vai ser discutido pessoalmente com as equipes e eu estou esperando isso tem seis meses (médico 3).

Pode-se inferir que a priorização da atenção básica para inversão do modelo assistencial não caminha sem mudanças efetivas na prática. Além disso, a coordenação e supervisão do trabalho das equipes de Saúde da Família em Juiz de Fora reiteram o modelo da administração científica (DIAS, 1999) porque a mesma acontece de forma hierárquica entre os gestores e trabalhadores das equipes, as relações de poder ficam estabelecidas em cascata entre os gestores, trabalhadores de nível superior e os trabalhadores de nível médio. E mais: a disseminação de informações no PSF em Juiz de Fora está em processo; percebeu-se que as informações são produzidas e existem concretamente. Entretanto, não são divulgadas e isso é justificado, pelos gestores, com a ausência de aparatos tecnológicos e inovações administrativas que ainda estão em projeto.

\section{Dimensão econômica}

Destacaram-se três temas: modalidades de vínculos, remuneração diferenciada e direitos sociais.

\section{Modalidades de vínculos}

Observou-se que os vínculos existentes se enquadram no regime celetista, pela Associação Municipal de Apoio Comunitário (AMAC), e de estatutário, com a Prefeitura de Juiz de Fora. Além desses há, entre os componentes das equipes de Saúde da Família, trabalhadores que foram municipalizados e cujo vínculo de origem é com a Secretaria Estadual de Saúde de Minas Gerais, como se verifica no enunciado a seguir (sic): "Meu vínculo inicial era do Estado, eu era estatutária, meu vínculo é com o Estado. Quando eu vim para Juiz de Fora eu já vim municipalizada [...] e aí teve uma chamada que iria iniciar o programa" (gestor 2).

Foram observadas evidências de que alguns trabalhadores, devido à remuneração, tendiam a buscar outras fontes de renda. Assim, eles trabalhavam nas equipes de Saúde da Família durante o dia e faziam plantões noturnos, tanto em organizações privadas como em outros setores do serviço de saúde do município. Isso demonstra que o vínculo com a Saúde da Família não é de 
dedicação exclusiva. O município utiliza sua força de trabalho de forma produtivista. Entende-se por produtivista uma força de trabalho voltada para a produção de procedimentos em saúde (de forma que estes possam ser contabilizados e garantam repasse financeiro para o município), uma vez que permite que os trabalhadores das equipes de Saúde da Família exerçam atividades em outro setor.

Segundo Roza e Rodrigues (2003, p. 72), no PSF “o gestor tem várias formas de contratação previstas em lei, podendo, dependendo de sua necessidade, optar pelo tipo de contratação que ofereça melhor custo-beneficio". Entretanto,

o gestor que tem responsabilidade tanto com o social quanto com o bem público conseguirá administrar as finanças a partir de decisões de como contratar seus recursos humanos, não perdendo de vista a importância de se adotar políticas de proteção do trabalho, evitando a precarização do vínculo (ROZA; RODRIGUES, 2003, p. 72).

Nesse sentido, o município, através de seu gestor, deve utilizar melhor o recurso público, valorizar seus recursos humanos e considerar o desenvolvimento de ações nessa área como investimento.

\section{Remuneração diferenciada}

Comentar sobre a remuneração da equipe, naquele momento, foi um tanto complicado para os trabalhadores. Alguns não se colocaram muito à vontade para falar de outras categorias, devido às disparidades salariais entre os integrantes das equipes, como fica claro no depoimento a seguir ( $\mathrm{sic}$ ):

A remuneração é péssima, péssima, péssima, ainda mais com esse plano agora. A do médico é quatro mil e poucos reais para quem está entrando agora, e a gente vai aposentar a gente de carreira na prefeitura na letra não sei quanto, com três mil e poucos reais (assistente social 2).

As diferenças salariais ocasionam conflitos entre as categorias que pertencem à Saúde da Família, criando obstáculos para o desenvolvimento adequado do trabalho. Isso ocorre porque o setor saúde, seja ele público ou privado, integra o setor de serviços e é profundamente influenciado pelas leis do mercado - ou seja, pela lógica de acumulação de capital e pelo 
desenvolvimento tecnológico, sobretudo da indústria farmacêutica e dos meios de diagnóstico (LEOPARDI, 1999). Essa dinâmica fortalece o modelo de atenção cuja concepção é a produção da cura, destacando, inclusive pela remuneração, o elemento central desse modelo, o qual detém o saber específico necessário para seu desenvolvimento.

\section{Direitos sociais}

A Constituição Federal de 1988 (BRASIL, 1988), em seu Capítulo II, Art. $7^{\circ}$, prevê direitos sociais aos trabalhadores que se inserem formalmente no mercado de trabalho, como férias, aposentadoria, décimo-terceiro salário, licenças diversas, entre outros benefícios.

Os trabalhadores das equipes de Saúde da Família do município de Juiz de Fora, sejam eles celetistas ou estatutários, possuem garantidos legalmente os direitos sociais necessários ao exercício da cidadania e à condição digna de trabalho. Esses mesmos trabalhadores, ao serem questionados com relação aos direitos conferidos por seu contrato de trabalho, demonstraram desconhecer quais seriam tais direitos. Pode-se inferir certa alienação dos mesmos quanto a seus direitos, enquanto trabalhadores.

O enunciado a seguir ratifica tal análise (sic):

E, aí dançou, eu não sei, dançou, com relação às licenças que tenho direito, mais o quê? Esse direito à licença para acompanhar pessoa da família, direito à folga se eu participo de algum evento fora do horário de trabalho, folga de vacina, que eu tenho direito, né? A gente não tem na realidade muito daquela preocupação, só quando a gente se depara com alguma situação é que a gente se pergunta: “A gente tem direito a quê?”(enfermeira 1).

$\mathrm{Na}$ atualidade, os direitos sociais se encontram ameaçados, pois eles são responsabilizados pela redução de investimentos na economia e vistos como obstáculos para o crescimento e desenvolvimento econômico dos países. A garantia desses direitos passa pelo cumprimento de leis que organizam as relações de trabalho. Concepções político-ideológicas defendem que, para as empresas, está cada vez mais difícil cumprir tais leis. Isso se deve ao alto custo dos encargos sociais e trabalhistas, o que acarreta novas formas de relações de trabalho, menos vantajosas para os trabalhadores (DUARTE; DINIZ; BARBIERI, 2000). 
Dentro dessa perspectiva, segundo o Seminário Anual dos Observatórios de Recursos Humanos de Saúde de Saúde, realizado em Brasília, de 16 a 18 de novembro de 2004, na Organização Pan-Americana de Saúde, com o trabalho decente - isto é, a ocupação que permite a homens e mulheres o equilíbrio entre trabalho e vida familiar, com remuneração que viabilize uma vida digna - nos serviços de saúde se evitariam o desgaste da força de trabalho, o estresse profissional e trabalhadores precocemente improdutivos (PIERANTONI, 2004).

Pode-se deduzir que os trabalhadores das equipes de Saúde da Família de Juiz de Fora se encontram como os demais trabalhadores de saúde, desprovidos de ações que considerem os recursos humanos em saúde como prioridade. Acredita-se que a melhoria nas condições de trabalho fomente a motivação para o trabalho em saúde, pois somente valorizando os trabalhadores será possível desenvolver uma atenção à saúde de qualidade e efetiva.

Finalmente, pode-se perceber que o trabalho das equipes de Saúde Família, analisado nas dimensões organizativa do processo produtivo, políticoideológica e econômica, respondeu à questão norteadora deste estudo, pois permitiu descrever como se estabelecem: a divisão de trabalho entre os componentes da equipe; a identificação de divergências e convergências de interesses do trabalho entre as equipes e dirigentes; e a remuneração e vínculos de trabalho de seus componentes.

Assim, essas constatações podem possibilitar o incremento de ações mais resolutivas pelos trabalhadores, pelos gestores e pelo controle social no processo de trabalho da atenção básica de saúde do município.

\section{Referências}

BRASIL. Constituição (1988). Constituição da República Federativa do Brasil. Brasília: Senado Federal, 1988.

BRASIL. Ministério da Saúde. As cartas da promoção da saúde. Brasília, 2002. Janeiro, 2001.

Gestão municipal de saúde: leis, normas e portarias atuais. Rio de

. Sistema de informação em atenção básica, 2005. Disponível em: <http://www.saude.gov.br>. Acesso em: 15 mar. 2005. 
CAMPOS, G. W. S. Subjetividade e administração de pessoal: considerações sobre os modos de gerenciar o trabalho em equipes de saúde. In: MERHY, E. E.; ONOCKO, R. (Orgs.). Agir em saúde: um desafio para o público. São Paulo: Hucitec, 1997.

DIAS, R. Sociologia e administração. Campinas: Alínea, 1999.

DUARTE, A.; DINIZ, A.; BARBIERI, A. (Orgs.). Dicionário da educação profissional. Belo Horizonte: Fidalgo \& Machado, 2000.

LEOPARDI, M. T. Processo de trabalho em saúde: organização e subjetividade. Florianópolis: Papa-Livros, 1999.

MINAYO, M. C. S. O desafio do conhecimento: pesquisa qualitativa em saúde. São Paulo: Hucitec, 1994.

MINTZBERG, H. Criando organizações eficazes: estruturas em cinco configurações. São Paulo: Atlas, 1995.

NOGUEIRA, R. P. O trabalho em serviços de saúde. In: Organização PanAmericana de Saúde. Desenvolvimento gerencial de unidades básicas do sistema de saúde. Brasília: OPAS, 1997. p. 182-186.

PIERANTONI, C. R. Relatório final. IN: SEMINÁRIO ANUAL DOS OBSERVATÓRIOS DE RECURSOS HUMANOS DE SAÚDE, nov. 2004. Processos de reforma setorial na região das Américas. Brasília, 2004.

ROZA, J. R.; RODRIGUES, V. A. O Programa de Saúde da Família e os vínculos institucionais externos. In: FALCÃO, A. et al. (Orgs.). Observatório de recursos humanos em saúde: estudos e análises. Rio de Janeiro: Fiocruz, 2003.

SANTANA, J. P. A gestão do trabalho nos estabelecimento de saúde: elementos para uma proposta. In: BRASIL. Ministério da Saúde. Gestão municipal de saúde: textos básicos. Rio de Janeiro, 2001. p. 219-234.

VASCONCELOS, E. M. Educação popular e a atenção à saúde da família. São Paulo: Hucitec, 1999.

YIN, R. K. Estudo de caso: planejamento e métodos. Porto Alegre: Bookman, 2003. 
Denise Barbosa de Castro Friedrich e Celia Regina Pierantoni

\section{NOTAS}

* Doutora em Saúde Coletiva pelo IMS-UERJ; professora adjunta na Faculdade de Enfermagem da Universidade Federal de Juiz de Fora, Minas Gerais. Endereço eletrônico: denisebcf@yahoo.com.br.

** Doutora em Saúde Coletiva pelo IMS-UERJ; professora adjunta no Departamento de Planejamento e Administração em Saúde do IMS-UERJ; diretora do Departamento de Gestão da Educação na Saúde do Ministério da Saúde. Endereço eletrônico: pieranto@ infolink.com.br.

${ }^{1} \mathrm{O}$ presente estudo é parte da tese de doutorado O trabalho em saúde: focalizando pessoas e processos nas equipes de Saúde da Família em Juiz de Fora, defendida no Instituto de Medicina Social da UERJ. 
The work of the Family Health Team: a view on the organizational dimensions of the productive, political, ideological and economical process in Juiz de Fora

This case study aims to analyze the work of the family health staff. Some interviews and direct observations were carried out within the teams. The organization of the productive process is related to an large division of tasks. The user's demands and health care are themes which guide this dimension. The political and ideological dimension is made of several power practices, and themes related to the assistance model, managerial model and exchange of information between teams support this dimension. The economical dimension, on its turn, is formed by different links and salaries to workers who share the same degree of responsibility. Within this dimension, the main themes were the categories of links, different salaries and social rights. This information can help improve more efficient actions, implemented by managers as well as by the social control on the primary attention within the municipal health system.

Key words: Public Health; Family Health Program; work/economics; workers; working conditions. 